\title{
Differenz
}

Revista internacional de estudios heideggerianos y sus derivas contemporáneas

AÑO 3 NÚMERO 2: JULIO DE 2016. e-ISSN: 2386-4877 - DOI: 10.12795/DIFFERENZ.2016.I02.09

[pp. 151-166]

Recibido: $17 / 05 / 2016$

Aceptado: 14/06/2016

\section{Heidegger y la fenomenología de la enfermedad}

\section{Heidegger and the phenomenology of illness}

\author{
Marco Sanz \\ Universidad Autónoma de Barcelona
}

\section{Resumen:}

El objetivo de este trabajo es elaborar una interpretación fenomenológica de la enfermedad con base en la analítica del Dasein. Partiendo de que entre la angustia y la enfermedad existe una analogía estructural, se pretende demostrar que la enfermedad es un modo eminente de apertura y, como tal, también conduce a la propiedad [Eigentlichkeit], si bien, a diferencia de la angustia, pasa por una experiencia explícita del cuerpo. Para ello, en este estudio se introduce la problemática de la corporeidad en el marco de la analítica del Dasein y se distingue la enfermedad del dolor.

Palabras Clave: fenomenología; enfermedad; cuerpo; Dasein; Heidegger. 


\section{Abstract:}

The aim of this paper is to elaborate a phenomenological interpretation of illness based on the Dasein's analytic. Considering that there is a structural analogy between illness and anxiety, this work tries to demonstrate that the first is also an eminent mode of disclosedness and that it also leads to the authenticity [Eigentlichkeit] but unlike anxiety, it goes through an explicit experience of the body. In order to prove that, the problem of the embodiment is approached from the Dasein's analytic and illness is differentiated from pain.

Keywords: phenomenology; illness; body; Dasein; Heidegger.

Hacia ${ }^{1}$ la mitad del $\S 49$ de Ser y tiempo, donde se delimita el análisis ontológico de la muerte frente a otras posibles interpretaciones del fenómeno, Heidegger deja abierta una pregunta más o menos en los siguientes términos: a la par de la muerte, ¿deberá acaso concebirse la enfermedad [Krankheit] primariamente como un existenciario [existenzial]? $?^{2}$ El que la cuestión se haya situado a esa altura de la obra quizás no sea mera casualidad, mucho menos el que se exponga justo antes de bosquejar el sentido ontológico de la muerte, pues teniendo en mente estos y otros detalles se columbra la posibilidad de establecer una analogía estructural entre los respectivos fenómenos de la angustia y de la enfermedad. Así, con el propósito de llevar a cabo esta tarea es preciso trazar las líneas directrices que deberán guiar la interpretación hacia una obtención fenomenológica del concepto de enfermedad.

En primer lugar, partiendo de que las estructuras movilizadas durante un proceso patológico coinciden con los de la angustia ante la muerte, pasaremos revista a la alternativa entre propiedad [Eigentlichkeit] e impropiedad [Uneigentlichkeit] del Dasein y la reinterpretaremos a la luz del concepto de ritmo. Esto permitirá evaluar la pertinencia

1. El presente trabajo se enmarca en un proyecto de investigación doctoral titulado Aproximación al estudio fenomenológico de la enfermedad a la luz del pensamiento del primer Heidegger, auspiciado por el Programa de Formación de Doctores Jóvenes de la Universidad Autónoma de Sinaloa (México).

2. Literalmente, Heidegger plantea así la pregunta: Oder müssen gar Krankheit und Tod überhaupt - auch medizinisch - primär als existenziale Phänomene begriffen werden? (¿ंO deberán acaso concebirse la enfermedad y la muerte en general -incluso en un plano médico- primariamente como fenómenos existenciarios*) [Heidegger, M. (1993): Sein und Zeit. Tübingen: Max Neimeyer Verlag, p. 247; Ser y tiempo, trad. cast. de Jorge Eduardo Rivera. Santiago de Chile: Editorial Universitaria, 2005, p. 268]. *Sólo en esto preferimos la versión de José Gaos que traduce existenzial por «existenciario». 
de otras estrategias metodológicas que contribuirían mejor a captar en su justa dimensión el tema de este artículo.

Por otro lado, puesto que el objetivo es preparar el terreno para una obtención fenomenológica de la enfermedad, se discute la insuficiencia del utillaje conceptual que la analítica del Dasein proporciona. La meta no es otra que justificar la necesidad de hacer del cuerpo un tema de interés para la ontología del Dasein. Después llevaremos a cabo un trabajo de delimitación de la enfermedad frente al dolor, fenómeno con el cual aquélla guarda cierta relación.

Una vez desarrollado los dos puntos anteriores, se acomete la tarea de intentar fijar fenomenológicamente el concepto de enfermedad.

1-Para determinar correctamente el sentido de la propiedad e impropiedad del Dasein quizás no haga falta especular tanto acerca de sus visos fácticos como sí recordar que, por cuanto ambas estructuras se insertan en el seno de la cotidianidad y, en ese sentido, responden a su dinámica, no son ni pueden ser operaciones cuyos resultados deban considerarse fijos o inamovibles. Propiedad e impropiedad van de la mano y generan asimismo esa sensación de secuencia intrínseca a la facticidad. Y en aras de elucidar la cuestión recorriendo otros caminos, querría arriesgar la siguiente hipótesis: entre los conceptos heideggerianos de propiedad e impropiedad y lo que Ortega y Gasset Ilama «ensimismamiento» y «alteración» existen interesantes coincidencias.

Llama primeramente la atención que lo que Ortega y Gasset sostiene acerca de la conducta humana evoca, en un sentido afín a Heidegger, la pregunta por el sujeto de la vida cotidiana. En efecto, la polaridad de ensimismamiento y alteración así lo explica: mientras uno de los extremos describe cómo los objetos y acaecimientos del contorno gobiernan la vida, el otro se refiere a una suspensión virtual y provisoria del mundo durante la cual se visualiza además una oportunidad de escoger de verdad ${ }^{3}$. En estado de alteración, el hombre «no rige su existencia, no vive desde sí mismo, sino que está siempre atento a lo que pasa fuera de él, a lo otro que él» ${ }^{4}$. Aunque la contraparte, i. e., el ensimismamiento, tenga para Ortega un ligero matiz intelectual, lo cierto es que en un estricto sentido formal se corresponde bastante bien con la propiedad, por cuanto describe ese instante en el que el hombre, quebrado el hechizo de su enajenación, cultiva su singularidad radical como única e insuperable condición de un comportamiento

3. Véase ORTEGA Y GASSET, J. (1972): El hombre y la gente I. Madrid: Revista de Occidente, pp. 32-35. 4. Ibídem, p. 34. 
que entra en pugna con el gregarismo. No obstante, Ortega y Gasset descarta que estos modos se anulen mutuamente, ya que, por un lado, la perspectiva última de quien se sabe ensimismado no es otra que la del mundo en torno, pues el motivo de su «retirada» o aislamiento es el de calibrar cómo grabar en el tejido de ese mundo la impronta de su inalienable individualidad, mientras que la alteración sólo es posible en virtud del ensimismamiento, y esto porque, de acuerdo con el meditador de El Escorial, el que el hombre goce del privilegio de poder liberarse al menos transitoriamente de las cosas depende del margen de seguridad y amparo al que su vida tiende esencial y ordinariamente. ¿Y no es este acaso un estado de cosas semejante al que Heidegger tiene en mente? ¿No se encuentra el Dasein inmediata y regularmente enajenado, es decir, consignado al mundo, dispersado en él, distraído hacia fuera, en lo otro que él? Amparar, tranquilizar y dar cobijo, ¿cuál, si no, es la función del uno? Más aún: ¿no expresa la propiedad, al igual que el ensimismamiento, una forma de afrontar el mundo que, a diferencia de la gregaria y anónima conducción del uno, se lleve a cabo en calidad de protagonista, es decir, un modo de plantar cara a la cotidianidad guiado por la firme convicción de no dejarse avasallar más por el mundo de los trebejos y las rutinas a fin de gobernarlo e imponerle así la voluntad y el designio propio? Pese a sus diferencias netas, esta es una de las zonas de confluencia que hay entre propiedad y ensimismamiento: indicar, que no concertar ideal concreto alguno, la sola posibilidad de trocar la sensación de seguridad que suministra ese manto tejido de hábitos y rutinas por la conmoción ante la repentina dificultad de no hallar otro asidero más que lo que se agita libre de prejuicios bajo la piel.

Esto legitima que tales fenómenos puedan ser interpretados como casos en los que el Dasein experimenta una subida de tono por lo que se refiere a la comprensión de sus posibilidades. Pero como advertimos que no son estados inamovibles, lo correcto es situarlos en el marco de una reflexión que afiance dicho dinamismo. La noción de ritmo aparece así como una estrategia metodológica pertinente, ya que, como se podrá ver a continuación, no sólo mantiene en su dimensión existenciaria tales conceptos, sino que además avala una vía de acceso al fenómeno de la enfermedad.

Si para Heidegger captar el sí mismo no es «un quedarse mirando fijamente al yo como si se tratase de un objeto, sino [...] el proceso de ganar y perder la vida una cierta familiaridad consigo misma» ${ }^{5}$, no es difícil suponer que semejante oscilación se articula bajo un determinado ritmo. Más aún: la prueba del discurrir de la vida fáctica tan sólo

5. HEIDEGGER, M. (2014): Problemas fundamentales de la fenomenología (1919/1920), trad. cast. de Francisco de Lara. Madrid: Alianza Editorial, p. 265. 
radica en «el ritmo del tener experiencia mismo» ${ }^{6}$. Desde este punto de vista, la disyuntiva entre los dos modos fundamentales de ser no tendría por qué guardar ningún misterio, en la medida en que simplemente describe el nivel de intensidad con el que son asumidas las vivencias. El número de lapsos que paso ensimismado, abarcando en una sola mirada el horizonte de mis posibilidades, presto a deliberar qué grado de responsabilidad merecen mis actos, así como el tiempo que consciente o inconscientemente invierto en realizar actividades que no exigen elevadas dosis de compromiso existencial, todo eso junto le otorga a mi vida ese ritmo personal justamente mío. El ritmo de vida que cada quien lleva no debe confundirse empero con una organización del tiempo en jornadas u horarios, hay que entenderlo como el reflejo fáctico de la relación - más que del equilibrio- que en cada caso se establece entre propiedad e impropiedad, entre ensimismamiento y alteración. La clave estaría en determinar qué fenómeno, por así decir, hace las veces de metrónomo.

Pues bien, si preguntáramos qué aspectos resultan directamente afectados por la acción de un estado de ánimo como la angustia - que, como también sabemos, presupone la inflexión de los parámetros de la impropiedad-, parece bastante lícito señalar la familiaridad, que constituye el fondo de inteligibilidad y comprensión del que se nutre la vida fáctica. ¿O no es ésta, según Heidegger, la que se derrumba en un acceso de angustia? «En la angustia - dice el filósofo- uno se siente desazonado» ^, da la sensación de estar fuera de casa. Recordemos además que la angustia, al desafiar la familiaridad con la que uno normalmente se conduce por la vida, coloca al Dasein cara a cara con su poder-ser más propio; en palabras de Heidegger: «revela su ser libre para la libertad de escogerse y tomarse a sí mismo entre manos» ${ }^{8}$. Resulta cómodo imaginar que durante su estado de alteración o impropiedad el Dasein vive en un deplorable enajenamiento, toda vez que el no tenerse entre manos sea interpretado como uno de los siniestros resultados de vivir bajo el yugo de la economía y siendo presa de la manipulación técnica y mediática. Sin embargo, esto es justo lo que se pretende evitar al ver la dinámica del comportamiento desde la perspectiva del ritmo. En la medida en que el mundo, y con él el clima de familiaridad que ahí se genera, no se manifiesta como una cosa presente y fija, sino que se diluye en el discurrir de la vida fáctica, lleva inscripto el ritmo de las vivencias mismas y, por lo tanto, sólo cabe experimentarlo directamente de esa manera rítmica ${ }^{9}$.

\section{Idem}

7. HEIDEGGER, M. (1993): Sein und Zeit, op. cit., p. 188; Ser y tiempo, op. cit., p. 210

8. Idem

9. Véase HeIDEGGER, M. (2008): La idea de la filosofía y el problema de la concepción del mundo, trad. cast. de Jesús Adrián Escudero. Barcelona: Herder, p. 119. 
Por esa razón, aun cuando la angustia suponga un repentino "colapso" de la familiaridad, el sentido profundo de su experiencia fáctica está lejos de desaparecer ${ }^{10}$, pues si bien la angustia aísla y abre al Dasein como un solus ipse, es necesario leer este solipsismo entre comillas, ya que

lejos de instalar a una cosa-sujeto aislada en el inocuo vacío de un estar-ahí carente de mundo, lleva precisamente al Dasein [...] ante su mundo como mundo, $y$, consiguientemente, ante sí mismo como estar-en-el-mundo ${ }^{11}$.

La misma idea aparece en Ortega y Gasset: después del ensimismamiento, dice el autor, en lugar de extraviar su mismidad en su «vuelta» al mundo, el hombre «lleva su sí mismo a lo otro, lo proyecta enérgica, señorialmente sobre las cosas, es decir, hace que lo otro - el mundo- se vaya convirtiendo poco a poco en él mismo» ${ }^{12}$. Dicho lo cual, la familiaridad aparece como un criterio para la articulación rítmica de la vida fáctica: si decrece, los episodios de propiedad son más largos; si incrementa, con ella asciende el nivel de alteración. Estar ensimismado, apropiarme expresamente de lo que soy, no significa levantar un muro entre yo y mi circunstancia, entre mis iniciativas y tendencias y el mundo al cual estoy consignado; se trata, por el contrario, de prestarle a esa consignación una atención distinta a la habitual. Se advierte allí que la libertad constitutiva del Dasein retiñe a una frecuencia tal que difícilmente puede pasar desapercibida. El tiempo y la periodicidad de cada estado dependerá por supuesto de las circunstancias en las que

10. Por lo tanto, conviene leer la expresión "colapso de la familiaridad" en un sentido figurado. Un autor que ha abordado la enfermedad retomando esta cuestión, es Frederik Svenaeus. En virtud de que el objetivo de la medicina es promover y restaurar la salud, este autor sugiere entender a ésta como un modo de "sentirse en casa", i. e., como lo que Heidegger llama Zuhause-sein, y propone, en consecuencia, que la enfermedad sea vista como una situación en la que el individuo deja de sentirse en casa, una suerte de Nichtzuhause-sein. Para ello, Svenaeus se apoya en el juego etimológico que en alemán permite la palabra Unheimlichkeit, que, como sabemos, al remitir a un no sentirse en casa expresa "la peculiar indeterminación del 'nada y en ninguna parte' en que el Dasein se encuentra cuando se angustia» [HEIDEGGER, M. (1993): Sein und Zeit, op. cit., p. 188; Ser y tiempo, op. cit., p. 210]. Así, de acuerdo con él, la Unheimlichkeit estaría en la base tanto de la angustia como de la enfermedad [véase SVENAEUS, F. (2000): The hermeneutics of medicine and the phenomenology of health. The Netherlands: Kluwer Academic Publishers, pp. 93-100]. Naturalmente, resulta bastante injusto tratar de sintetizar en una nota el planteamiento de toda una obra. No obstante, y sin dejar de reconocer que el conjunto del trabajo de Svenaeus nos parece metodológicamente interesante, lo cierto es que no consigue evitar moverse en el marco de la tradición, pues no sólo la enfermedad es vista con matices peyorativos, sino que un concepto clásico de salud ejerce sobre él un discreto encanto. Por tanto, al dejarse impregnar demasiado de connotaciones ónticas, palidece su rigor fenomenológico.

11. HeIDEGGER, M. (1993): Sein und Zeit, op. cit., p. 188; Ser y tiempo, op. cit., p. 210.

12. ORTEGA Y GASSET, J. (1972): El hombre y la gente I, op. cit., p. 38. 
cada quien vive; pero su incesante convergencia redunda siempre en la sensación de que la vida fluye bajo determinado ritmo.

Toca el turno de preguntar ahora si la angustia es la única capaz de desazonar al Dasein. ¿Es que no hay acaso otros temples o experiencias en las que ese clima de familiaridad se debilite dejando tras de sí la certeza de que "el camino de vuelta a casa» pasa por un afrontar la libertad de decidir sin el auxilio ajeno? ¿No será que la enfermedad, sobre todo el padecimiento grave, es una forma de apelación al poder-ser más propio del Dasein? O dicho de otra manera: ¿hasta dónde es posible sostener que la enfermedad supone la proposición de un ritmo seriado por largos ensimismamientos que acortan los episodios de alteración?

2-Con la interpretación del comportamiento desde la perspectiva del ritmo, advertimos que el sistema de ideas y creencias que constituye la impropiedad y dentro del cual el Dasein se deja alterar no está a salvo de fisuras ni de conflictos. Verlo en suspenso puede significar para el Dasein un verdadero problema vital. En la medida en que el ser humano no puede mantener siempre el clima de familiaridad entre él y su mundo o instalarse definitivamente en un contexto de seguridad y firmeza, en el cual sepa a qué atenerse respecto de su entorno y de sí mismo, el carácter de un problema vital no es primariamente técnico ni intelectual sino práctico: su solución, antes de ser una idea o el fruto de una doctrina, nace de la acción, del franco ejercicio del cuidado ${ }^{13}$. Así, decidir ejecutivamente cuál ha de ser el modo de "volver a casa" induce a pensar que la familiaridad es para la vida fáctica lo que el metrónomo para un compositor. La angustia, a título de estas metáforas, vendría a retener del lado del ensimismamiento el pulso de la aguja. Sin embargo, es difícil sostener que ese carácter retentivo sea exclusivo de la angustia, sobre todo porque, anticipándonos un poco a lo que vendrá enseguida, un examen fenomenológico de la enfermedad conduce a una descripción del movimiento de apropiación de sí mismo, pero que, a diferencia de lo que sobreviene a raíz de la angustia, se ejecuta de un modo considerablemente distinto.

Pues bien, ¿qué ocurre, desde el punto de vista del comportamiento, durante un proceso patológico? Tenemos, en primera instancia, el paso de un estado a otro: uno se encuentra saludable y se siente bien y de pronto o paulatinamente enferma y va sintiéndose mal. Poco importa determinar la polaridad de bienestar y malestar si lo que se busca es el sentido formal de la enfermedad. Reténgase tan sólo el paso, la transición de un estado a otro que la experiencia enseña. Pero aún no sabemos en qué consiste ese

13. Véase MARíAS, J. (1969): Introducción a la filosofía. Madrid: Revista de Occidente, pp.31-32. 
tránsito. El primer paso estriba en demostrar que éste no trastoca lo que, de acuerdo con Heidegger, constituye el anillo estructural de la existencia: el mundo circundante, el mundo compartido y el mundo del sí-mismo. Dicho en otras palabras: no porque la enfermedad describa el paso de un estado a otro estos tres aspectos dejan de figurar en el horizonte de comprensión. Y sin embargo, ello no significa que el Dasein no perciba un cambio «real» en el sentido global de su existencia. Se trata más bien de proponer que la modificación se lleva a cabo a nivel de la experiencia concreta que en cada caso el Dasein tiene de dicho nexo. Más aún: la sensación de que la enfermedad marca un antes y un después se genera como consecuencia de lo que ella interrumpe o posibilita en referencia a un plexo de significatividad, o bien, a partir del modo en que interviene la dispersión que el Dasein experimenta como parte de su caída en el mundo, pues es justamente la caída la que entrelaza y ciñe el mundo con los hilos de la familiaridad. ¿Qué es entonces lo que la enfermedad interrumpe o posibilita? ¿Cuál es el contexto fenoménico que aquí comienza a despuntar?

2.1-Si convenimos ahora "que la enfermedad es siempre un modo de vivir reactivo a una alteración del cuerpo» ${ }^{14}$, es necesario determinar cómo tiene que darse la experiencia sólita de la corporeidad para que en ella pueda producirse una reacción de esa índole, es decir, el estado que llamamos «enfermedad». Y si hemos dicho que ésta no altera el anillo estructural del Dasein, ¿̇qué es, pues, lo que ocurre con la facticidad vista desde el cuerpo cuando ella atraviesa por la situación de enfermar? Y en todo caso, ¿̇en qué nos basamos para decir que el proceso patológico, aun cuando suponga ese «modo de vivir reactivo", no perturba la dimensión tripartita de la vida fática? Esta serie de preguntas nos sugieren ahora que el contexto fenoménico en el cual la enfermedad se circunscribe no puede caracterizarse suficientemente si se pasa por alto un análisis del fenómeno de la corporeidad, toda vez que el cambio de estado que evidencia el proceso patológico parece tener en esta última su nota esencial.

Como sabemos, en Ser y tiempo Heidegger se refiere muy de pasada al problema del cuerpo a propósito de la espacialidad del Dasein. Sin embargo, el que fuera más bien parco en sus observaciones no significa que no calibrara la magnitud del problema. Con todo, no fue hasta la edición de los Seminarios de Zollikon que las ideas que tuvo acerca de ello fueron objeto de una creciente popularidad. Allí, por ejemplo, acuñó el neologismo "corporar»[Leiben] para elucidar que los límites del cuerpo físico nunca

14. laín entralgo, P. (1968): El estado de enfermedad. Esbozo de un capítulo de una posible antropología médica. Madrid: Editorial Moneda y Crédito, p. 84. 
coinciden con los del cuerpo vivido y que, por tanto, todo lo que ocurre con esa "doble dimensión" de la corporeidad se funde a su vez con el sentido global de las vivencias ${ }^{15}$. Así, la naturaleza limítrofe de estos dos registros corporales no puede ser sino cualitativa, lo cual se explicaría ya sea aludiendo a la tendencia esencial del Dasein a la cercanía, o bien, analizando el papel que el cuerpo cumple a la hora de abordar la problemática del sí mismo ${ }^{16}$.Por eso merece una mención especial lo que Heidegger destaca en otro sitio: la característica esencial del curso vital - escribe ahí- está dada «por la necesaria referencia a la corporeidad [Leiblichkeit]». Y dicha corporeidad -agrega una página después- no sólo configura un "estrato fundamental en la corriente vital», sino que tiene además «la función de desencadenar determinados entramados motivacionales» ${ }^{17}$. Un ejemplo de ello sería la enfermedad, pero también el dolor - con el cual, por cierto, aquélla guarda un parentesco empírico.

Partamos, pues, del siguiente principio: "el estar-en-el-mundo como tal es un corporar ${ }^{18}$. El hecho de que el Dasein se encuentre ya en tal o cual circunstancia, en la que comúnmente queda absorto en medio de múltiples ocupaciones gracias a un clima de familiaridad, supone asimismo que él no es ninguna criatura etérea e inasible, sino que gran parte de sus iniciativas y tendencias se ejecutan únicamente porque tienen en la corporeidad un fundamento irrenunciable. No hay acción que no pase, aunque sea mínimamente, por una experiencia del cuerpo. Pero, debido a que «la inclinación hacia la caída es la responsable de que la vida fáctica [...] no pueda ser generalmente vivida como tal $/{ }^{19}$, esto es, como un auténtico y libre poder-ser, se infiere que la experiencia del cuerpo también es absorbida por la impropiedad: de ordinario el cuerpo sólo es vivenciado en la medida en que se pone al servicio de la alteración; la noción que tenemos de él es implícita la mayoría de las veces. Del cuerpo me valgo, por ejemplo, para hacer ejercicio,

15. Véase heIDEgGer, M. (2007): Seminarios de Zollikon. Protocolos - Diálogos - Cartas, trad. cast. de Ángel Xolocotzi. México: Jitanjáfora, p. 134-135.

16. Paul Ricouer llamó la atención sobre este punto al preguntarse si no habría que volverse hacia Ser y tiempo para elaborar una ontología del cuerpo que tuviera en cuenta la cuestión del sí mismo y su apertura al mundo. Véase RICOEUR, P. (1996): Sí mismo como otro, trad. cast. de Agustín Neira Calvo. México: Siglo xxi, pp. 362-365.

17. HEIDEgGeR, M. (1987): Zur Bestimmung der Philosophie, Gesamtausgabe, Band 56/57. Frankfurt am Main: Vittorio Klostermann, p. 210-211. Gander observa que estas breves anotaciones de Heidegger apuntan ya hacia el lugar de una tematización de la corporeidad basada en la consideración del sí mismo como función de la experiencia del vivir. Véase Gander, H.-H. (2008): "La fenomenología hermenéutica del vivir fáctico de Heidegger» (trad. cast. de Francisco de Lara) en Duque, F. (ed.). Heidegger. Sendas que vienen I. Madrid: Ediciones Pensamiento-UAM, p. 166.

18. HEIDEGGER, M. (2007): Seminarios de Zollikon, op. cit., p. 267.

19. HEIDEGGER, M. (2002): Interpretaciones fenomenológicas sobre Aristóteles. Indicación de la situación hermenéutica [Informe Natorp], trad. cast. de Jesús Adrián Escudero. Madrid: Trotta, p. 41 
para comer, para tomar un descanso, para solicitar asistencia médica o para entregarme simplemente a la tentadora faena de no hacer nada; y en todos esos casos la consciencia que tengo de mí se define a partir de las cosas y de lo que hago estando en medio de un ámbito de significatividad. No soy yo propiamente el que, para llevar a cumplimiento cada una de esas actividades, reparo en el anclaje corpóreo de mi estar-en-el-mundo, sino que dejo deslizar mis miembros y el cuerpo entero a propósito de las numerosas posibilidades de dispersión.

El estado corpóreo refleja así la tensión entre el cuidado y la caída y, por esa misma razón, se convierte en un punto de referencia y sustracción del ritmo, puesto que de la corporeidad también se deduce la idea según la cual la vida fáctica sólo es tal en la medida en que genera y modifica un orden de experiencia. Pero, ¿cómo se integra la experiencia del cuerpo en la corriente vital?

Si tenemos en cuenta la génesis del orden y no nos basamos en un orden ya hecho, el ritmo no sólo significa: 'Hay algo que se repite', sino también: 'Algo sólo existe repitiéndose'20.

Dentro de este género cabe incluir el cuerpo, pues nunca es idéntico, sino que deviene idéntico ${ }^{21}$ : sólo "es» en la medida en que está siendo identificado constantemente al volver mi mirada hacia él en tanto que «mi cuerpo». Todo lo cual permite colegir que el cuerpo es, como he optado por llamarlo, el «vector de la facticidad»: la cifra de músculos y huesos del estar-en-el-mundo que, como tal, contribuye a determinar en cada caso el nivel de intensidad con el que son asumidas las posibilidades y el arrojamiento.

Así, tenemos por un lado la noción de un cuerpo impropio, que si bien está ahí en su carnosa totalidad, no alcanzamos a percibir de él sino las partes que estarían destinadas a la acción, pues piénsese en lo difícil que sería vivir si tuviéramos que sentir necesariamente el movimiento de todas nuestras entrañas, la linfa circulando por los vasos, la sangre arteriosa galopando desde el corazón hasta los dedos, señales eléctricas propagándose a lo largo de la compleja red nerviosa. Y luego está la noción de un cuerpo propio, es decir, el amasijo de carne y tendones que, al filo de un ensimismamiento forzado por vísceras y nervios, asalta el drama de la facticidad para reclamar y ejercer su protagonismo.

20. WALDENFELS, B. (2015): Exploraciones fenomenológicas acerca de lo extraño, trad. cast. de Gustavo Leyva et. al. Barcelona: Anthropos, p. 82.

21. Ídem. 
2.2-Es de destacar, según lo anterior, que dentro de todos esos modos de manifestarse hay unos en los que el cuerpo, en un sentido análogo a la angustia, sitúa al Dasein ante la posibilidad de tomar entre manos su vida y frenar así su proclividad a la caída. Anticipamos que el dolor y la enfermedad ejemplifican bien lo que el cuerpo es capaz de desencadenar en el seno de la facticidad. Pero dolor y enfermedad no son términos intercambiables, por la sencilla razón de que existen padecimientos de cuyo cuadro clínico el primero no forma parte ${ }^{22}$. En ese sentido, es necesario delimitar ambos conceptos esbozando una caracterización de las coordenadas ontológicas donde cabría localizar el fenómeno del dolor para después señalar sus divergencias en relación a la enfermedad.

Pues bien, a) respecto del dolor es imposible que quepa cualquier género de duda: el dolor simplemente es o no es. Al presentarse, se vuelve ineludible hasta que llega el alivio. Semejante carácter de ineludibilidad es compartido con la enfermedad, especialmente por lo que se refiere a su fase crítica. b) Por otro lado, mientras el dolor concita el rechazo, la enfermedad propone a la vida un ritmo distinto al que tenía antes del padecimiento. Así, llamémosle transitoriedad a este segundo carácter: la atenazante realidad del dolor sólo es soportada «en vista de» su superación ${ }^{23}$; lo que no necesariamente ocurre durante la enfermedad, pues una persona puede estar enferma y vivir aceptándolo sin mayores problemas $^{24}$. Por tener el carácter de la transitoriedad, el dolor es incompatible con la vida; la enfermedad, en cambio, sí puede serlo. c) Conforme a la fórmula según la cual "[e]l dolor expresado nunca es el dolor vivido» ${ }^{25}$, otro aspecto ontológico del dolor es su refractariedad al lenguaje. Y de la enfermedad, generalmente, no sólo cabe determinar un nombre, sino que con él se define un cuadro clínico y, por ende, un espectro semiológico.

22. Véase LÓPEZ IBOR, J. J. (1954): «El escándalo del dolor» en El descubrimiento de la intimidad y otros ensayos. Madrid: Aguilar, pp. 224-225. Cabe advertir que el dolor del que hablaremos aquí no es aquel que numerosos autores vuelven tema de consideración filosófica. En efecto, no es ese dolor barnizado con gruesas capas metafísicas, ese dolor que convenimos en llamar "ontalgia» por cuanto remite al dolor de ser, sino la experiencia lesiva stricto sensu, aquélla que comúnmente se asocia a la vivencia morbosa y cuya raíz es fisiológica, es decir, aquel dolor que conmina a las personas a buscar alivio, bien por medio de la automedicación, bien a través de la asistencia médica.

23. En palabras de Buytendijk, la aceptación del dolor se ejerce «en beneficio» de otra cosa, supone la proyección hacia un estado donde éste ha sido mitigado o ha desaparecido dejando en su lugar la sensación de haber superado una dura prueba o un difícil obstáculo. Véase BUYTENDIK, F. J. J. (1958): El dolor. Psicología - fenomenología - metafísica, trad. cast. de Fernando Vela. Madrid: Revista de Occidente, p. 232.

24. Salvo que el dolor alcance per se el rango de enfermedad. Véase LERICHE, R. (1942): La cirugía del dolor, trad. cast. de J. Marin de Bernardo y E. Velilla Mateo. Madrid: Morata, pp. 57-86.

25. LE BRETON, D. (1999): Antropología del dolor, trad. cast. de Daniel Alcoba. Barcelona:Seix Barral p. 48 
d) Por último, tanto la enfermedad como el dolor contraen la insustituible singularidad de la existencia, esto es, acentúan el carácter de ser-cada-vez-mío del Dasein.

Como no podemos detenernos a elaborar exhaustivamente la caracterización de estas coordenadas, daremos por válida la distinción entre enfermedad y dolor y subrayemos tan sólo el común denominador: intensificar el rasgo de insustituible singularidad. Resulta un hecho incontestable el que, por más honda que pueda ser la empatía entre dos personas, nunca un familiar, un médico o un enfermero podrá sentir en carne propia la enfermedad o el dolor que un paciente experimenta en la suya. La enfermedad o el dolor que padezco es cada vez el mío, y desde luego lo es por un motivo muy fundamental: yo sólo existo en tanto que sujeto encarnado, el sentido pleno de mi facticidad vive de su anclaje corpóreo ${ }^{26}$.

A la vista de estos resultados, la opinión de que la analítica del Dasein no proporciona el suficiente utillaje conceptual para abordar la problemática del cuerpo puede objetarse si se retoma la noción de "vector de la facticidad». La tarea que surge enseguida consiste en insertar las reflexiones precedentes en el marco de una consideración fenomenológica de la enfermedad.

3-Con el propósito entonces de atar cabos sueltos y ensayar finalmente una obtención fenomenológica del concepto de enfermedad, recapitulemos de manera sumaria lo obtenido hasta aquí: a) como consecuencia de un proceso de ganancia y pérdida de familiaridad, la experiencia de la vida fáctica se articula bajo un determinado ritmo que oscila entre dos polos; b) ese proceso donde la familiaridad funge como variable no sólo tiene en la angustia un factor de corrosión, la enfermedad cumpliría un papel análogo, pero a diferencia de lo que ocurre con la disposición afectiva fundamental, en aquélla el recogimiento pasaría por una experiencia insólita de la corporeidad; c) y, entendiendo el cuerpo como vector de la facticidad, resta aclarar cómo en la enfermedad también se da la posibilidad de un apertura privilegiada.

26. Sobre la noción de "sujeto encarnado» en el contexto de la fenomenología, especialmente en la obra de Maurice Merleau-Ponty, véase ESCRIBANO, X. (2004): Sujeto encarnado y expresión creadora. Aproximación al pensamiento de Maurice Merleau-Ponty. Bacerlona: Prohom Edicions, pp. 93-212. Asimismo, sobre los puntos de convergencia entre Merleau-Ponty y Heidegger por lo que se refiere a la fenomenología del cuerpo y para una discusión acerca de la supuesta ausencia de una tematización expresa del cuerpo en la obra heideggeriana véanse, respectivamente, ASKAY, $R$. (2009): "Heidegger, the body, and the french philosophy» en Continental Philosophy Review, 32, pp. 29-35 y ADRIÁN ESCUDERO, J. (2011): «Heidegger y el olvido del cuerpo» en Lectora, 17, pp. 181-198. 
Una de los puntos cardinales de la teoría de Canguilhem acerca de lo normal y lo patológico reza así:

Si lo normal no tiene la rigidez de un hecho de obligación colectiva sino la flexibilidad de una norma que se transforma en su relación con condiciones individuales, es evidente que la frontera entre lo normal y lo patológico se hace imprecisa ${ }^{27}$.

Esto no significa que la cuestión se desplace hacia un burdo relativismo. Que la frontera entre ambos valores sea imprecisa se explica por razones que desafortunadamente no podemos abordar aquí. Rescatemos tan sólo esa noción según la cual lo normal es un dato flexible. Ello remite a que cada quien sabe, desde luego, dónde termina su salud y dónde inicia la enfermedad. Canguilhem sostendrá que el individuo se vuelve el juez de esa transformación que desemboca en el estado de enfermedad porque nadie más que él la padece, lo que tiene lugar "en el preciso momento en que se siente inferior a las tareas que la nueva situación le propone ${ }^{28}$. Si miramos tal «inferioridad» como el reflejo de cierta disposición corporal e intentamos leerla en clave ontológica, tendríamos que el tránsito de la salud a la enfermedad implica hacer la experiencia del ser como posibilidad. El simple hecho de sentirme resfriado me dice que no soy el mismo de antes: algo pasó que el péndulo en el cual me balanceaba estando sano oscila a un ritmo distinto: el mal cuerpo parece forzarme al reposo, la constipación me obliga a hacer cosas de las que antes prescindía, el malestar se agudiza lo suficiente para pensar seriamente en tomarme el día libre. No es que la enfermedad borre completamente de mi horizonte posibilidades con las que estoy familiarizado o que degrade mi esencia proyectante; la comprensión que tengo de mí, de los otros y de mi entorno permanece intacta: si bien puedo hacerlo con algún grado de dificultad debido a las molestias, visualizo y manejo los utensilios al igual que lo hacía antes del catarro; del mismo modo, pese a los síntomas, puedo desplegar mi existencia incluyendo la figura del otro dentro de mis confines prácticos; pero eso sí: tengo una consciencia más explícita de tener que habérmelas con mi ser. La enfermedad desborda así el flujo de la alteración al proponer posibilidades que, al estar cernidas expresamente por la disposición del cuerpo, fuerzan a que el Dasein se reincorpore partiendo de su inalienable individualidad. $Y$ a diferencia de la angustia, que retrotrae al Dasein hacia su poder-ser más propio sin necesidad de una referencia explícita

27. CANGUilhem, G. (2009): Lo normal y lo patológico, trad. cast. de Ricardo Potschart. México: Editorial Siglo xxi, p. 138.

28. Ídem. 
a la corporeidad ${ }^{29}$, en la enfermedad la "disminución" de la familiaridad se manifiesta como un efecto de la resistencia del cuerpo a seguir comportándose como si nada pasara.

Por lo tanto, así como acreditamos una disposición afectiva, un encontrarse anímicamente templado, así también cabe pensar en una disposición corpórea, toda vez que el cuerpo no es descubierto mediante un rodeo reflexivo sino que se presenta irreflexivamente en el mundo del que nos cuidamos. Al igual que el anímico, el estado corporal patentiza ya el estar-en-el-mundo como un todo posibilitando además un primario "dirigirse a...». Tal es el sentido del "corporar». En la enfermedad, esta estructura despierta de su estado latente, pues el clima familiar en el cual se efectuaba luce desbordado y, en consecuencia, el Dasein es remontado hacia su poder-ser: una suerte de ensimismamiento domina la escena y el sentido global de la situación se plantea como una pregunta: cómo asumir el hecho de tener que ser soportando el peso de la enfermedad. ¿No es este acaso un modo eminente de apertura? Partiendo del hecho de estar enfermo, no se trata tanto de comprobar que mi disposición corpórea le pone límites a lo que puedo llegar a hacer como de situarme ante la posibilidad de asumir que la encrucijada de contingencia y finitud en la que consiste mi vida me concierne con tal radicalidad que me resulta muy difícil no prestarle atención.

Con base en lo anterior, parece bastante lícito afirmar que la manifestación más plena de la enfermedad coincidiría con ese momento en el que las posibilidades que se ejecutan son menores que las que aspiran a ejercerse. Por tanto, el fenómeno "enfermedad» no describe algo que pudiera ser aprehendido en una vivencia privada que el individuo tuviera de su más recóndito fuero interno. Tampoco el yo o el sí mismo implícito en la emisión de frases del tipo "estoy enfermo» o "me siento mal» hace referencia al sujeto como si fuese éste una cápsula o un ente desgajado de un plexo de significatividad. Si «enfermo» es el adjetivo que acompaña al enunciado, entonces el sujeto muestra la totalidad del mundo que se ha visto intervenido por la enfermedad.

Resta enfatizar que aun cuando el ejemplo del resfriado sea demasiado simple, su aspecto formal puede hacerse extensivo a casos severos en la medida en que, fenomenológicamente hablando, no es necesario adherirse a un criterio de salud. El problema de fondo residía en demostrar cómo la enfermedad suma al ritmo de la

29. Véase WARSOP, A. (2011): "The ill body and das Unheimliche (the uncanny)» en Journal of Medicine and Philosophy, 36, p. 491. Por otro lado, que la angustia dé pie a un desplazamiento hacia la corporeidad, es algo que demuestra López Ibor, sin embargo cabe aclarar que la índole de su análisis, si bien mantiene cierta afinidad con el planteamiento heideggeriano, es estrictamente psicopatológica. Véase López Ibor, J. J. (1966): Las neurosis como enfermedades del ánimo. Madrid: Gredos, pp. 103-105. 
corriente vital una nueva nota. En rigor, la enfermedad no interrumpe ni libera nada, ocurre simplemente que, como observara Heidegger a propósito de la angustia, revela al Dasein su estar libre para la libertad de empuñar personalmente las posibilidades a las cuales se ve referido en tanto que sujeto encarnado. En otras palabras: en la enfermedad, semejante apertura no se cristaliza sino como un reenvío de la vida fáctica hacia su «vectorización» corporal, lo cual adopta y se confunde incluso con el principio estructural que hace del Dasein esencialmente un poder-ser.

\section{Bibliografía}

ADRIÁN ESCUDERO, J. (2011): «Heidegger y el olvido del cuerpo» en Lectora, 17, pp. 181198.

ASKAY, R. (2009): "Heidegger, the body, and the french philosophy» en Continental Philosophy Review, 32, pp. 29-35.

BUYTENDIK, F. J. J. (1958): El dolor. Psicología-fenomenología-metafísica, trad. cast. de Fernando Vela. Madrid: Revista de Occidente.

CANGUilhem, G. (2009): Lo normal y lo patológico, trad. cast. de Ricardo Potschart. México: Editorial Siglo xxi.

ESCRIBANO, X. (2004): Sujeto encarnado y expresión creadora. Aproximación al pensamiento de Maurice Merleau-Ponty. Bacerlona: Prohom Edicions.

GANDER, H.-H. (2008): «La fenomenología hermenéutica del vivir fáctico de Heidegger» (trad. cast. de Francisco de Lara) en Duque, F. (ed.). Heidegger. Sendas que vienen I. Madrid: Ediciones Pensamiento-UAM.

HeIDeggeR, M. (1987): Zur Bestimmung der Philosophie, Gesamtausgabe, Band 56/57. Frankfurt am Main: Vittorio Klostermann.

HEIDEGGER, M. (2005): La idea de la filosofía y el problema de la concepción del mundo, trad. cast. de Jesús Adrián Escudero. Barcelona: Herder.

HEIDEGGER, M. (2002): Interpretaciones fenomenológicas sobre Aristóteles. Indicación de la situación hermenéutica [Informe Natorp], trad. cast. de Jesús Adrián Escudero. Madrid: Trotta.

HEIDEgGeR, M. (2014): Problemas fundamentales de la fenomenología (1919/1920), trad. cast. de Francisco de Lara. Madrid: Alianza Editorial. 
HeIdegger, M. (2007): Seminarios de Zollikon. Protocolos - Diálogos - Cartas, trad. cast. de Ángel Xolocotzi. México: Jitanjáfora.

HEIDEGGER, M. (1993): Sein und Zeit. Tübingen: Max Neimeyer Verlag; Ser y tiempo, trad. cast. de Jorge Eduardo Rivera. Santiago de Chile: Editorial Universitaria, 2005.

Laín ENTRAlgo, P. (1968): El estado de enfermedad. Esbozo de un capítulo de una posible antropología médica. Madrid: Editorial Moneda y Crédito.

LE BRETON, D. (1999): Antropología del dolor, trad. cast. de Daniel Alcoba. Barcelona: Seix Barral.

LERICHE, R. (1942): La cirugía del dolor, trad. cast. de J. Marin de Bernardo y E. Velilla Mateo. Madrid: Morata.

LÓPEZ IBOR, J. J. (1954): «El escándalo del dolor» en El descubrimiento de la intimidad y otros ensayos. Madrid: Aguilar.

LÓPEZ IBOR, J. J. (1966): Las neurosis como enfermedades del ánimo. Madrid: Gredos.

MARÍAS, J. (1969): Introducción a la filosofía. Madrid: Revista de Occidente

ORTEGA Y GASSET, J. (1972): El hombre y la gente I. Madrid: Revista de Occidente.

RicoeUR, P. (1996): Sí mismo como otro, trad. cast. de Agustín Neira Calvo. México: Siglo xxi.

SVENAEUS, F. (2000): The hermeneutics of medicine and the phenomenology of health. Netherlands: Kluwer Academic Publishers.

WALDENFELS, B. (2015): Exploraciones fenomenológicas acerca de lo extraño, trad. cast. de Gustavo Leyva et. al. Barcelona: Anthropos.

WARSOP, A. (2011): "The ill body and das Unheimliche (the uncanny)» en Journal of Medicine and Philosophy, 36, p. 484-495 